IMDS

117,9

1800

Received 13 March 2016

Revised 5 June 2016

Accepted 13 July 2016

\section{A new risk assessment model for agricultural products cold chain logistics}

\author{
Hao Zhang \\ Business School, Beijing Technology and Business University, Beïing, China, and \\ Bin Qiu and Keming Zhang \\ School of Economics and Management, Beijing Jiaotong University, Beijing, China
}

\begin{abstract}
Purpose - The purpose of this paper is to develop a quantitative risk assessment method for agricultural products cold chain logistics to assess the condition of the fresh agricultural products cold chain process objectively and accurately.

Design/methodology/approach - A risk assessment index system of agricultural products cold chain logistics is designed on the basis of the risk identification for the process of agricultural products cold chain logistics. This paper first uses catastrophe progression method and a new maximum deviation method to build an improved catastrophe progression assessment model for agricultural products cold chain logistics. In order to verify the reliability and validity of the model, two representative enterprises are selected as the case in the study. Findings - The results in the empirical research indicate strong support for the assessment model and coincide with the reality. The risk assessment index system can also reflect the key risk factors from agricultural products cold chain logistics scientifically. In addition, the improved catastrophe progression assessment method proposed in this paper can be scientific and reasonable to predict risk.

Research limitations/implications - This paper contributes to provide a new risk assessment model for agricultural products cold chain logistics. The new model overcomes the limitation of subjective empowerment and it increases the objectivity and scientificity in the process of cold chain logistics risk assessment. This paper also shows that practitioners involved in the field of products cold chain logistics can manage the potential risk by a set of scientific methods for assessing the risk before the accident.

Practical implications - The paper provides a practical guideline to practitioners, especially for cold chain logistics managers, relevant management departments, and cold chain logistics management consultants. It is proved that the new risk assessment method and the risk assessment index system of agricultural products cold chain logistics can help them assess the risk scientifically and reasonably.

Originality/value - Although the calculation is simple, the new model can overcome the limitation of subjective empowerment scientifically and reasonably, and thus has important practical value.
\end{abstract}

Keywords Agricultural products cold chain logistics, Improved catastrophe progression method,

New maximum deviation method, Risk assessment model

Paper type Research paper

\section{Introduction}

In recent years, with the overall improvement of people's living standards, consumers demand for the market of fresh agricultural products has been expanded rapidly and food safety issues has also been a great deal of attention. Fresh agricultural products have some characteristics, such as a short shelf life, great demand of the market, high requirements for storage and transportation technology, so the appropriate operation mode and efficient information management system play an important role in ensuring products quality, especially in the

(c) Hao Zhang, Bin Qiu and Keming Zhang. Published by Emerald Publishing Limited. This article is published under the Creative Commons Attribution (CC BY 4.0) licence. Anyone may reproduce, distribute, translate and create derivative works of this article (for both commercial \& non-commercial purposes), subject to full attribution to the original publication and authors. The full terms of this licence may be seen at: http://creativecommons.org/licences/by/4.0/legalcode

This research was supported by the Project of National Social Science Foundation of China (15BGL202) and the Project of Beijing Philosophy and Social Science (17GLB013). 
stage of cold chain logistics (Manning et al., 2006; Jin et al., 2013). As the intermediate links of consumers and suppliers, cold chain logistics play a very important role in terms of quality of agricultural products. However, there is a big risk in the logistics operation of each link since fresh agricultural products in the process of the cold chain logistics operation are not completely under the certain specific environment, so it is vital to study how to assess the risk of cold chain logistics objectively and accurately and avoid the risk effectively.

For decades, with the development of technology boom and the rise of globalization trend, cold chain logistics has got a systematic promotion and application, and it has formed a comprehensive and integrated cold chain system. The earliest and most fruitful field research on cold chain logistics is the study of the pharmaceutical cold chain logistics. Then, it has been gradually extended to the cold chain logistics of processed food and agricultural products. At present, most scholars research on cold chain logistics mainly concentrate in the field of technology. From the perspective of technology, Lixin et al. (2013) proposed a new enzymatic Time-temperature indicators (TTI ) based on enzyme reaction and diffusion. They proved the new TTI has a good stability and reliability at dynamic storage conditions and it could be used to monitor the fresh products during the cold chain logistics. Yujun et al. (2015) put forward a monitoring and decision system based on wireless sensor networks (WSN) and ontology which presents great advantages such as effective regulation, low power consumption, and accurate ontology-based analysis. Kuo and Chen (2010) developed an advanced multi-temperature joint distribution system for the food cold chain, which provides a new scheme for continuously temperature-controlled logistics. It can also jointly deliver and store multi-temperature goods. In order to improve the efficiency of monitoring system for frozen and chilled aquatic products, a temperature monitoring system based on WSN with compressed sending was developed, which provides effective decision support traceability for quality and safety assurance of frozen and chilled aquatic products (Xinqing et al., 2016). Xinqing et al. (2015) also indicated that the WSN and adaptive optimal weighted data fusion methods could effectively reflect the real-time temperature and quality property. Xuefeng et al. (2012) proposed a new cold chain logistics system based on cloud computing, which can be used to link the database between cold chain logistics with external customers. It can accelerate the speed of cold chain logistics and maximize the interests of all parties.

At present, the academic research on agricultural products cold chain logistics has not yet built a complete research system and it mainly focuses on the cold chain logistics technology and temperature controlling, such as the methods and means to maintain a stable temperature in the process of refrigerated and frozen (Shabani et al., 2012). Abad et al. (2009) demonstrate the intercontinental logistics chain of fresh fish and put forward the application of RFID smart labels for food cold chain monitoring and analysis. Hans Rediers et al. (2008) use experiments show that small fluctuations in supply chain was little affected on temperature, but a great influence on microbial activity that affected the quality and safety of agricultural products. A wireless sensor network can be used to monitor the milk temperature in the process of transportation, which makes the microprocessors, wireless transmitting device and battery placed within the milk bottle cap (Carullo et al., 2009). James et al. (2006) elaborate the modeling of food temperature, microbial growth and other parameters in the transportation of food. Since fresh agricultural products can cause huge losses in the process of transportation, an "intelligent container" is able to precisely monitor the condition of agricultural products, as well as track its geographical position (Lutjen et al., 2013). By doing berry logistics field studies, Cecilia et al. (2014) show that a significant reduction of up to 98 percent in the root-mean-square-error difference between the product temperature and air temperature, which has a great improvement in logistics quality of fresh fruit and vegetable. For the research of cold chain performance assessment, Defraeye et al. (2016) propose a comprehensive performance evaluation of the
A new risk assessment model 
IMDS

117,9

fresh-produce cold chain by studying the ambient loading of citrus in refrigerated containers. Joshi et al. (2011) develop a Delphi-AHP-TOPSIS-based benchmarking framework to evaluate the fresh products cold chain performance of a company.

As for the field of risk assessment and management, scholars have done a lot of academic studies, especially in quantitative research. Grassi et al. (2009) and Cieslak (2011) propose a method of risk assessment model based on fuzzy logic theory. A fault tree analysis method is proposed to assess the different target risk (Caputo et al., 2004; Acosta and Forrest, 2009; Gierczak, 2014). Wang and Elhag (2006) design a fuzzy topsis method based on $\alpha$ level sets and presents a nonlinear programming solution procedure to assess the risk of bridge. Liyuan et al. (2010) researched the ingestion risks of metals in groundwater based on TIN model and dose response. Fabre et al. (2006) according to the bayesian modeling of aphid population dynamics studied the risk of barley yellow dwarf disease. In conclusion, abundant studies focused on the methods of risk assessment and their application in various fields has been relatively mature.

In the literature, though there are many papers researching on cold chain logistics, most of them are mentioning cold chain technology, especially in the temperature control technology. There are few scholars to study the cold chain logistics from the perspective of risk assessment. On the other hand, different methods of risk assessment have their own characteristics and advantages, but most of them exist subjective bias of decision-making process and the final results. Therefore, using a scientific method to analyze the system risk of agricultural products cold chain logistics is a kind of breakthrough itself. This paper takes the system risk of agricultural products cold chain logistics as the research object and combines catastrophe progression method, which is the important application branch of catastrophe theory, with the maximum deviation method to construct the assessment model of agricultural products cold chain logistics risk based on the improved catastrophe progression method. The example analysis proves that the assessment model of improved catastrophe progression can be used to overcome the strong subjectivity and difficult operation in the traditional assessment method, and the result does not lose scientificity and rationality. Moreover, the model can locate the specific risk system of agricultural products cold chain logistics precisely, and it has important practical and promotional value.

The remainder of the paper is organized as follows: in the second section, the applicability of catastrophe theory for the risk system of agricultural products cold chain logistics is discussed, and the assessment model of improved catastrophe progression is constructed by introducing the method of maximum deviation. We build the risk assessment index system of agricultural products cold chain logistics in the third section. Two agricultural products cold chain logistics enterprises are selected to verify the model in the fourth section. In the conclusion section, we analyze the results, and summarize the limitations of this study and some possible directions of future researches.

\section{Methodology: an improved catastrophe progression model}

\subsection{The basic principle and steps of catastrophe progression method}

As one of the three theories of new system science, catastrophe theory was proposed by French famous mathematician Rene Thom in the late 1960s. Regarding the topology as a tool, based on the structural stability theory, catastrophe theory belongs to a kind of complexity science theory, which is based on numerous cross mathematical methods (Golubitsky, 1978). In the process of system from a stable configuration to another, catastrophe theory aims to reveal the objective laws of thing qualitative change through the study on the stability of structure of things. Although the theory is based on complex mathematical, it is not difficult to understand its application model, so the theory is well used for decades in the field of natural sciences, biology and social sciences. Potential system is the main object of catastrophe theory research, which depends on the interaction 
of each component in the system and the relevance size of the system and the external environment which can be, respectively, described by state variables and control variables (O'Shea, 2001). Rene Thom proves that there are only seven types of catastrophe when the number of state variables is not more than 2 and the number of control variables is no more than 4 , which are cusp catastrophe, swallowtail catastrophe, fold catastrophe, butterfly catastrophe, oval umbilical point catastrophe, hyperbolic umbilical point and parabolic umbilical point catastrophe, respectively (Zeeman, 1979).

Catastrophe progression method, which combines catastrophe theory with fuzzy mathematics, is used to assess the target comprehensively. The biggest characteristic of this method is that it does not need to give weight to each index. On the contrary, this method takes into account the relative importance of each index, thus it reduces the subjectivity, yet scientific and rational, and its calculation is simple, which has important practical value. This is also the reason why the catastrophe progression method is selected as methodology in this paper. First of all, according to the requirements of catastrophe progression method, the target body is decomposed based on the importance of multifactor and multi-level to establish the objective subject of hierarchical structure model. And then catastrophe fuzzy subordinate function is deduced by the catastrophe theory and fuzzy mathematics, and the normalized formula is hierarchically calculated and a parameter is resulted, which is called the total catastrophe fuzzy subordinate function value. In the process of catastrophe progression comprehensive assessment, the lower hierarchical assessment index is considered as a control variable of the upper hierarchical assessment index.

\subsection{The applicability of catastrophe theory for agricultural products cold chain logistics}

As a widespread phenomenon in the nonlinear complex system, catastrophe is a kind of discontinuous state transition process which is caused by the continuous change of the external environment. By the definition of agricultural products cold chain logistics, it is known that there are various factors affecting the degree of system risk for agricultural products cold chain logistics and these factors affect the entire risk system individually or collectively. Therefore, the risk system of agricultural products cold chain logistics is a complex system composed of many factors. The system undergoes continuous and discontinuous changes through the complex nonlinear relationship between various factors. As a result, agricultural products cold chain logistics risk appears in the form of gradual change or catastrophe, and it would be easy to make its logistics risk changes suddenly when several influence factors of the system vary at the same time. In general, the characteristics of external systems can be divided into more stability, sudden jump, hysteresis, unreachability, divergence, and catastrophe theory can be used to study the system if the external state of a system satisfies two or more features.

As a part of the system theory, catastrophe theory has the integrity and scientific in the analysis of the system of agricultural products cold chain logistics, which has a complex structures of "person - fresh agricultural products - environment."

\subsection{Construction for catastrophe progression model}

2.3.1 Building a hierarchical structure assessment model based on the index system. According to the requirements of the catastrophe progression method, decomposition should be done inside the research target system to establish a hierarchical assessment index system composed of multiple factors. Because a certain state variables corresponding to the number of control variables is no more than four in the existing types of seven kinds of elementary catastrophe functions now, the number of index in each hierarchy structure should not exceed more than four (Zhang et al., 2009).
A new risk assessment model

1803 
IMDS 117,9

1804
Before using catastrophe progression method to assess, we should take each index into the order according to their importance. In order to overcome the subjectivity of various index sequence, the maximum deviation method is introduced to calculate the weight of each index to realize the minimized subjective bias for the final assessment results. The basic principle of the method of maximum deviation is to get results by calculating the ratio size of the total deviation of a specific index and the total deviation of all indexes in the system. The higher is the ratio, the greater is the importance (Wang, 1998). Though maximum deviation method is suitable for the sequence of various indexes from the risk system especially, the use of this method often only consider variable weight which are caused by the differences between property values. Instead, it ignores the attribute weight for the assessment index itself. Therefore, the maximum deviation method is improved in this paper. The new method considers variable weight and attribute weight at the same time.

The improved maximum deviation method can be described as follows.

Step1: dimensionless processing for the original data of the underlying index. The Min-Max standardized processing method is used in the paper. If it is a positive index, the higher value is better, and the data can be shown as:

$$
z_{i j}=\frac{p_{i j}-p_{\min }(j)}{p_{\max }(j)-p_{\min }(j)}
$$

If it is a reverse index, the lower value is better, and the data can be represented as:

$$
z_{i j}=\frac{p_{\max }(j)-p_{i j}}{p_{\max }(j)-p_{\min }(j)}
$$

where $P_{i j}$ represents the raw data for the No. $i$ assessment object and the No. $j$ assessment index. $P_{\max }(j)$ represents the maximum number of index $j . P_{\max }(j)$ represents the minimum number of index $j . z_{i j}$ represents an index value after standardization process.

And where:

$$
i \in N=\{1,2, \cdots, n\}, \quad j \in M=\{1,2, \cdots, m\} .
$$

Step2: establishing the solving model of improved maximum deviation method for the optimal weight vector. Assuming that the variable weight vector and attribute weight vector of a specific hierarchy, respectively, are $W^{*}=\left(w_{1}^{*}, w_{2}^{*}, \cdots, w_{m}^{*}\right)$ and $W=\left(w_{1}, w_{2}, \ldots, w_{m}\right)$. The decision matrix after standardized procession is labeled $Z=\left(z_{i j}\right)_{n \times m}$. Then standardized weighted decision matrix can be determined as follows:

$$
D=W^{*} \cdot W \cdot Z=\left[\begin{array}{cccc}
w_{1}^{*} w_{1} z_{11} & w_{2}^{*} w_{2} z_{12} & \cdots & w_{m}^{*} w_{m} z_{1 m} \\
w_{1}^{*} w_{1} z_{21} & w_{2}^{*} w_{2} z_{22} & \cdots & w_{m}^{*} w_{m} z_{2 m} \\
\vdots & \vdots & \vdots & \vdots \\
w_{1}^{*} w_{1} z_{n 1} & w_{2}^{*} w_{2} z_{n 2} & \cdots & w_{m}^{*} w_{m} z_{n m}
\end{array}\right]
$$

For a specific index $j$, setting $d_{i j}$ as the sum of the deviation of a specific assessment object $i$ and all other assessment objects in the same index. So $d_{i j}$ can be defined as the following:

$$
d_{i j}=\sum_{k=1}^{n}\left|w_{j}^{*} w_{j} z_{i j}-w_{j}^{*} w_{j} z_{k j}\right| \quad(i=1,2, \cdots, n ; j=1,2, \cdots, m)
$$


The sum of the deviation of index $j$ can be represented as:

$$
d_{j}=\sum_{i=1}^{n} d_{i j}=\sum_{i=1}^{n} \sum_{k=1}^{n}\left|z_{i j}-z_{k j}\right| \cdot w_{j} \cdot w_{j}^{*}(j=1,2, \cdots, m)
$$

So the total deviation of the index system can be described as follows:

$$
d_{i j}^{*}=\sum_{j=1}^{m} d_{j}=\sum_{j=1}^{m} \sum_{i=1}^{n} \sum_{k=1}^{n}\left|z_{i j}-z_{k j}\right| \cdot w_{j} \cdot w_{j}^{*} \quad(i=1,2, \cdots, n ; j=1,2, \cdots, m)
$$

Based on the above analysis, we can construct a deviation optimization model combined with the related conditions. The model can be described as follows:

$$
\left\{\begin{array}{l}
\max d_{i j}^{*}=\sum_{j=1}^{m} \sum_{i=1}^{n} \sum_{k=1}^{n}\left|z_{i j}-z_{k j}\right| \cdot w_{j} w_{j}^{*} \\
\text { s.t. } w_{j} \geqslant 0, j \in T, \sum_{j=1}^{m} w_{j}^{2}=1
\end{array}\right.
$$

Step3: solving the deviation optimization model. Processing Formula (6) by Lagrange method, we can get result as following:

$$
L\left(w^{*}, \delta\right)=\sum_{j=1}^{m} \sum_{i=1}^{n} \sum_{k=1}^{n}\left|z_{i j}-z_{k j}\right| \cdot w_{j} \cdot w_{j}^{*}+\frac{1}{2} \delta\left(\sum_{j=1}^{m} w_{j}^{* 2}-1\right)
$$

Then using partial derivative to deal with Formula (7) and we can get optimal parameters as Formula (8) by introducing the normalization process to solve the partial derivative result:

$$
w_{j}^{*}=\frac{\sum_{i=1}^{n} \sum_{k=1}^{n}\left|z_{i j}-z_{k j}\right| \cdot w_{j}}{\sqrt{\sum_{j=1}^{m}\left[\sum_{i=1}^{n} \sum_{k=1}^{n}\left|w_{j} z_{i j}-w_{j} z_{k j}\right|\right]^{2}}}
$$

The weight vector $W^{*}=\left(w_{1}^{*}, w_{2}^{*}, \cdots, w_{m}^{*}\right)$ is the optimal solution.

Step4: for a multi-level structure of assessment index system, the importance of the upper index will be decided by the total utility value from the corresponding lower indexes. The total utility value is equal to the sum of the product of the corresponding index weight value (both variable weight and attribute weight) and its relevant assessment object data.

2.3.2 Determine the different types of catastrophe system for assessment objective. Rene Thom in his catastrophe theory proves that when the state variable is in one-dimensional there are four kinds of elementary catastrophe model. They are: cusp catastrophe, swallowtail catastrophe, fold catastrophe and butterfly catastrophe. 
IMDS

117,9

1806

When the control variable is one-dimensional, it is a fold catastrophe and its potential function can be represented as follows:

$$
f(x)=x^{3}+a x
$$

When the control variable is two-dimensional, it is a cusp catastrophe and its potential function can be represented as follows:

$$
f(x)=x^{4}+a x^{2}+b x
$$

When the control variable is three-dimensional, it is a swallowtail catastrophe and its potential function can be described as follows:

$$
f(x)=\frac{1}{5} x^{5}+\frac{1}{3} a x^{3}+\frac{1}{2} b x^{2}+c x
$$

When the control variable is four-dimensional, it is a butterfly catastrophe and its potential function can be described as follows:

$$
f(x)=\frac{1}{6} x^{6}+\frac{1}{4} a x^{4}+\frac{1}{3} b x^{3}+\frac{1}{2} c x^{2}+d x
$$

where $f(x)$ represents the potential function of catastrophe system; $x$ represents a state variable of catastrophe system; $a, b, c, d$ represent the different control variables for the state variable and their order is determined by their degree of importance (Figure 1).

2.3.3 Deducing the normalization formula by bifurcation equations of catastrophe system. According to the catastrophe theory, equilibrium surface is a set of all critical points of potential function, and its equation is $f^{\prime}(x)=0$. The singular set equation of equilibrium surface can be described by $f^{\prime \prime}(x)=0$. Then the equations $f^{\prime}(x)=0$ and $f^{\prime \prime}(x)=0$ are synthesized to get the equations of bifurcation points set, which indicates that they are the focus of the catastrophe theory research. The bifurcation equation can be expanded in the form of decomposition and the normalization formula would be deduced ultimately. There are three common normalization formulas in the catastrophe system.

Normalization formula for the cusp catastrophe system can be represented as:

$$
x_{a}=a^{1 / 2}, x_{b}=b^{1 / 3}
$$

Normalization formula for the swallowtail catastrophe system can be represented as:

$$
x_{a}=a^{1 / 2}, x_{b}=b^{1 / 3}, x_{c}=c^{1 / 4}
$$

Normalization formula for the butterfly catastrophe system can be represented as:

$$
x_{a}=a^{1 / 2}, x_{b}=b^{1 / 3}, x_{c}=c^{1 / 4}, x_{d}=d^{1 / 5}
$$

Figure 1.

Three common types of catastrophe structure

\section{Swallowtail catastrophe}

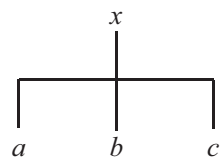

Butterfly catastrophe

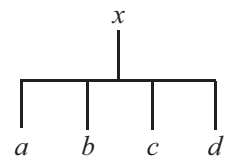


2.3.4 Decision selected principles for catastrophe system. In the end, we can get the total catastrophe subordinate function value by calculating the different levels of evaluation index hierarchically with the normalization formulas. As for the choice of decision variables in the calculation process, we combine with the multi-objective fuzzy decision theory and follow two basic principles, which are complementary principle and non-complementary principle, according to the different direction that the control variables impact on the state variable. When the control variables in the system relate to each other, we will choose complementary principle and the value of the state variable is equal to the average value of the corresponding different control variables after normalization calculation. Instead, when the control variables in the system do not relate to each other, we will choose non-complementary principle and the value of the state variable is equal to the minimum value among the corresponding different control variables after normalization calculation (Chen and Yang, 2013).

\section{Assessment index system of agricultural products cold chain logistics risk}

\subsection{The basic principles of assessment index system construction}

Construction assessment index system of agriculture products cold chain risk is the basis for the study of this paper, only when a reasonable assessment index system of agriculture products cold chain risk is designed and key risk indexes are selected can its cold chain logistics risk be measure accurately. In order to build a comprehensive index system to reflect the various levels of agriculture products cold chain logistics risk, we identify five basic principles to ensure the objectivity and reliability of the assessment results:

(1) Scientificity: the construction of the assessment index system must be combined with the basic characteristics of agricultural products cold chain logistics so that the final assessment results can scientifically and reasonably reflect the degree of the system risk on the premise of scientificity.

(2) Systematicness: the systematicness of assessment index system requires that each index can measure the degree of agricultural products cold chain logistics risk from different angles and dimensions.

(3) Hierarchy: since the system of the agriculture products cold chain logistics risk is an extremely complex body composed of multi-factor, multi-index, and multi-level, and the components of the system should be subdivided in accordance with the degree of influence for each index to build an intuitive and clear index architecture.

(4) Comparability: various indexes selected in the index system should be able to compare their risk transversely and highlight their own characteristics in order to increase the accuracy and authenticity of the assessment results.

(5) The availability of its data: because the ultimate goal of establishing index system is on its quantitative analysis, various indexes and their data should be readily available to get the corresponding objective assessment results.

\subsection{Analysis of risk identification based on the decomposition method}

The decomposition is such a method for process analysis that a complex system is decomposed into a plurality of relatively simple and concrete elements, subsystems or sub-thing and we can have a more in-depth understanding of the whole system through a detailed analysis of the elements. In order to identify the key risk elements of agricultural products cold chain logistics objectively and increase the generality of the index system, we introduce the decomposition method to analyze the vegetable cold chain logistics mode in the USA, which is the most representative of the agricultural cold chain logistics circulation mode around the world, and its vegetable will enter a complete chain constituted by 
IMDS 117,9

1808

"process precooling-controlled atmosphere cold storage-cold chain transportationrefrigerated sales- supermarket insulation- family freezer" immediately as soon as it is picked from the field. Through the in-depth analysis of its distribution model, we can find that this process is mainly composed of four links which are freeze cutting, freezing storage, transportation and distribution and cold storage sales.

As shown in Figure 2, this flow chart can be found that agricultural products chain logistics operation mainly involves four elements in the process of processing, storage, transportation and sale, which are technology application, organization and management, facilities and equipment, external environment. In order to further obtain the specific risk factors that affect agricultural products cold chain logistics system, a specific and comprehensive analysis of the constituent elements can be made. Details are as follows:

- Technology application: advanced technology and standard operating procedures will seriously affect the quality of agricultural products in the cold chain logistics process because the entire process chain logistics was required to be in a low temperature environment, for example, the condition of temperature control system and equipment will directly affect the temperature environment. The technology is needed in the whole process, such as preservation technology, process detection technology, packaging technology, temperature control technology and so on.

- Organization and management: it necessarily requires personnel involvement as long as there is a place of commodity circulation and transaction. However, an actual risk often happens associated with mishandling of a little detail, so personnel organization is one of the core constituent elements of agricultural products cold chain logistics system. The incidence of cold chain failures during per unit of time,

Figure 2.

A typical flow chart of international agricultural products cold chain logistics

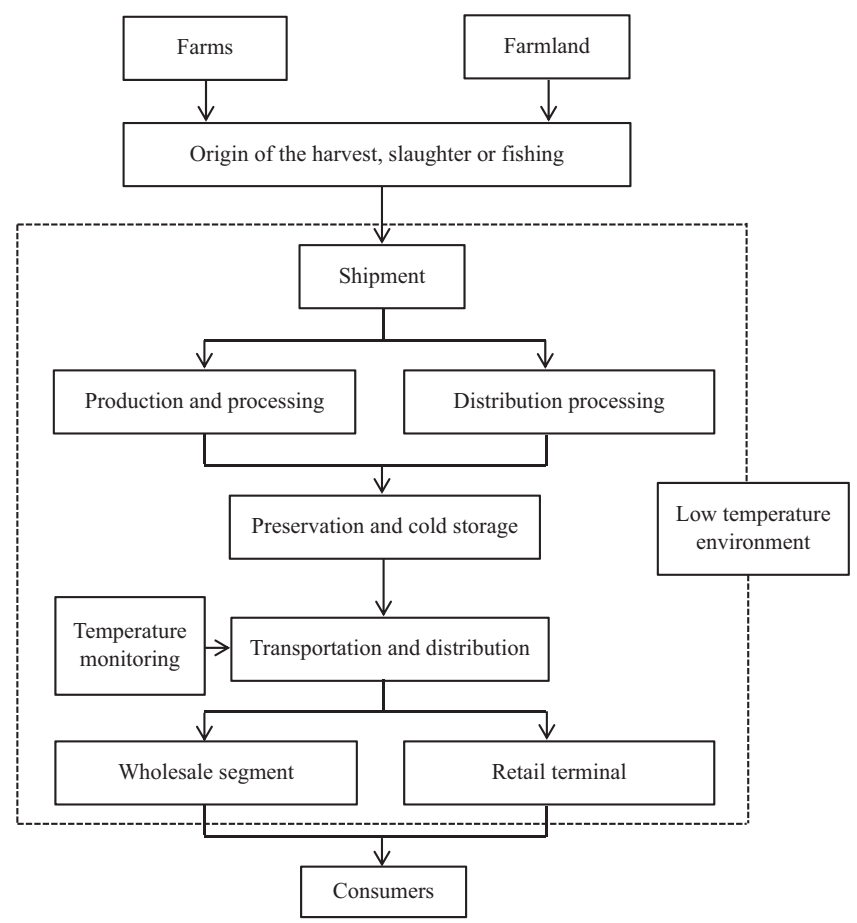


the structure of human resources and professional level for employees should be all used to measure the quality of the personnel organization processes.

- Facilities and equipment: as a carrier for the whole process, facilities, and equipment is an integral component in agricultural products cold chain logistics. The main use of equipment in the process includes temperature control equipment, transport equipment, sorting equipment, processing equipment and storage devices, such as cold storage, refrigerated trucks, etc., and the road transport facilities and distribution centers integrated facility are also needed. These facilities and equipment play a very important role in the cold chain logistics throughout the process.

- External environment: agriculture products cold chain in the entire logistics process must be in contact with the external environment for the exchange of relevant information and energy, and the external factors mainly are the stability of supply and demand, road traffic congestion, weather and climate conditions, etc. The present stage of the "broken" phenomenon occurs frequently which is caused largely due to these external uncertainty factors.

\subsection{The determination of assessment index}

Through the above analysis and reference to the relevant literature, as well as consultation to experts, we determine four primary indexes to measure the size of the risk for agricultural products cold chain logistics system, and on this basis, subdivided them into 11 secondary indicators to construct the risk assessment index system, which are temperature control equipment $(A 1)$, detection equipment $(A 2)$, cold storage capacity $(A 3)$, transportation equipment $(A 4)$, delay rate during distribution $(B 1)$, wastage rate during distribution $(B 2)$, road traffic conditions $(C 1)$, the stability of the supply $(C 2)$, administration system $(D 1)$, the proportion of professional talents $(D 2)$, incidence of cold chain failure $(D 3)$. The concrete structure is shown in the figure below (Figure 3).

In this index system, the delay rate of distribution can be measured by the ratio of the delay times to the total times. Similarly, the breakage rate of distribution process is equal to the ratio of the damaged goods volume to the total cargo volume in the process of delivery. Road traffic conditions mainly include the overall smooth degree of the road and the road construction standards. The structure of human resources will be an assessment according to the proportion of intermediate-senior professionals and the percentage of employees trained by professional knowledge. The incidence of cold chain failure can be defined as the ratio of cold chain failure times to the total circulation times per unit time.

\section{Empirical research and discussion of findings}

\subsection{Sample selection and calculation}

In order to verify the reliability and applicability for this improved catastrophe progression risk assessment model, we regard fresh agricultural products cold chain logistics from Shuanghui Group and Beijing Xinfadi as the research object. By collecting the two companies' cold chain logistics related data and expert assessment results, as well as The Cold Chain Logistics Development Report published by China Cold Chain Committee in recent years, we get the related nearly five years data of Shuanghui and Beijing Xinfadi agricultural products cold chain logistics. Meantime we invite experts in the field of cold chain logistics to assess each index of cold chain and attribute weight vector $(0.12,0.12,0.12$, $0.12,0.08,0.08,0.075,0.075,0.07,0.07$, and 0.07 ) can be obtained.

First of all, we can get the initial value of catastrophe membership function according to the Formulas (1) and (2) on the original data dimensionless processing. Then we should calculate the size of the importance for each index from same floor according to improved 
IMDS

117,9

1810

Figure 3.

Assessment index system of agricultural products cold chain logistics risk

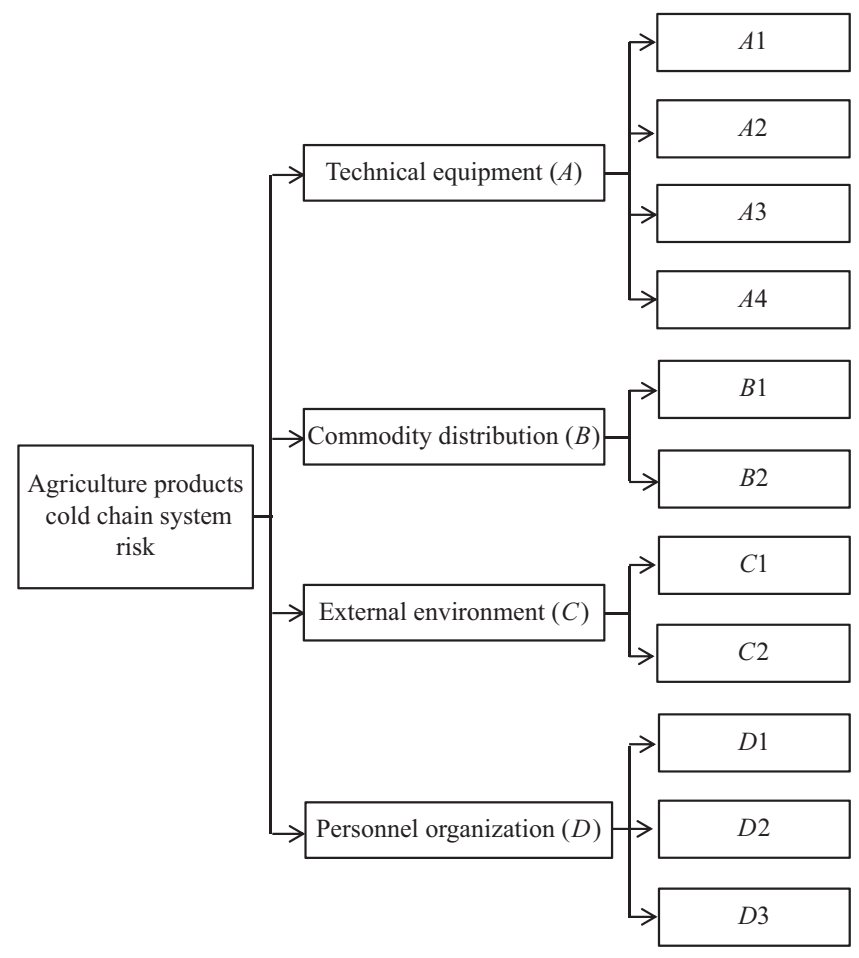

maximum deviation method and Formula (8), as well as the size of the total utility value corresponding to the upper index. The specific calculation results are shown in the Table I.

The figures in parentheses represent the respective weight of each index or total utility value for upper index. Data of Shuanghui (SH) in 2010, for example, its calculation process is shown as follows.

Four indexes from the technical equipment system, $A 1, A 2, A 3$ and $A 4$, constitute the butterfly catastrophe model of non-complementary type, and the importance of them is $A 1>A 3>A 4>A 2$. According to the Formula (11), we can calculate as follows:

$$
X_{A 1}=\sqrt{A 1}=\sqrt{0.0578}=0.2404,
$$

\begin{tabular}{cccccccccccccc}
\hline & \multicolumn{1}{c}{$A(8.76)$} & \multicolumn{4}{c}{$D(4.36)$} & \multicolumn{4}{c}{$B(4.00)$} & \multicolumn{2}{c}{$C(3.71)$} \\
& & $A 1$ & $A 3$ & $A 4$ & $A 2$ & $D 2$ & $D 3$ & $D 1$ & $B 2$ & $B 1$ & $C 1$ & $C 2$ \\
Area & & Years & $(0.5240)$ & $(0.4992)$ & $(0.4895)$ & $(0.4864)$ & $(0.6011)$ & $(0.5914)$ & $(0.5375)$ & $(0.7698)$ & $(0.6383)$ & $(0.7637)$ & $(0.6456)$ \\
\hline \multirow{2}{*}{ SH } & 2010 & 0.0578 & 0.3810 & 0.0000 & 0.1384 & 0.1504 & 0.0500 & 0.3204 & 0.8525 & 0.7832 & 0.0847 & 0.1538 \\
& 2011 & 0.4682 & 0.5238 & 0.3231 & 0.3899 & 0.6541 & 0.4500 & 0.4854 & 0.8852 & 0.6084 & 0.2034 & 0.1308 \\
& 2012 & 0.7659 & 0.5714 & 0.6462 & 0.6164 & 0.8571 & 0.4778 & 0.7961 & 0.8689 & 0.9021 & 0.3051 & 0.3000 \\
& 2013 & 0.9277 & 0.6310 & 0.9385 & 0.8994 & 1.0000 & 0.8500 & 0.8641 & 0.9180 & 0.8112 & 0.7288 & 0.4692 \\
& 2014 & 1.0000 & 0.7143 & 1.0000 & 1.0000 & 0.9173 & 1.0000 & 1.0000 & 1.0000 & 1.0000 & 1.0000 & 0.7923 \\
XFD & 2010 & 0.0000 & 0.0000 & 0.1692 & 0.0000 & 0.0000 & 0.0000 & 0.0000 & 0.1803 & 0.0000 & 0.0000 & 0.0000 \\
& 2011 & 0.3613 & 0.0000 & 0.2769 & 0.1572 & 0.1654 & 0.1778 & 0.1650 & 0.0000 & 0.5105 & 0.1864 & 0.1538 \\
& 2012 & 0.6561 & 0.0595 & 0.4308 & 0.3208 & 0.4060 & 0.4333 & 0.4272 & 0.2787 & 0.3497 & 0.4746 & 0.2769 \\
& 2013 & 0.8410 & 0.1667 & 0.6308 & 0.4403 & 0.4586 & 0.5667 & 0.4951 & 0.3770 & 0.4056 & 0.5932 & 0.3923 \\
& 2014 & 0.9220 & 1.0000 & 0.7385 & 0.6541 & 0.6165 & 0.8556 & 0.5825 & 0.3443 & 0.4615 & 0.9153 & 1.0000 \\
& & & & & & & & & & & & \\
\hline
\end{tabular}

Table I.

Different index value after standardized processing 


$$
\begin{gathered}
X_{A 3}=\sqrt[3]{A 3}=\sqrt[3]{0.3810}=0.7249 \\
X_{A 4}=\sqrt[4]{A 4}=\sqrt[4]{0.0000}=0.0000 \\
X_{A 2}=\sqrt[5]{A 2}=\sqrt[5]{0.1384}=0.6783 \\
X_{A}=\min \left(X_{A 1}, X_{A 2}, X_{A 3}, X_{A 4}\right)=0.0000
\end{gathered}
$$

Three indexes from the personnel organization system, $D 1, D 2$ and $D 3$, constitute the swallowtail catastrophe model of complementary type, and the importance of them is $D 2>D 3>D 1$. According to the Formula (10), we can obtain the results as follows:

$$
\begin{gathered}
X_{D 2}=\sqrt{0.1504}=0.3878, \\
X_{D 3}=\sqrt[3]{0.0500}=0.3684, \\
X_{D 1}=\sqrt[4]{0.3204}=0.7523, \\
X_{D}=\operatorname{average}\left(X_{D 2}, X_{D 3}, X_{D 1}\right)=0.5028
\end{gathered}
$$

Two indexes from the product supply system, $B 1$ and $B 2$, constitute the cusp catastrophe model of complementary type, and the importance of them is $B 2>B 1$. According to the Formula (9), we can get the results as follows:

$$
\begin{gathered}
X_{B 2}=\sqrt{0.8525}=0.9233, \\
X_{B 1}=\sqrt[3]{0.7832}=0.9218, \\
X_{D}=\operatorname{average}\left(X_{B 2}, X_{B 1}\right)=0.9225
\end{gathered}
$$

Similarly, $C 1$ and $C 2$ from the external environment system also constitute the cusp catastrophe model of non-complementary type, and their important order is $C 1>C 2$. According to the Formula (9), we can obtain the results as follows:

$$
\begin{gathered}
X_{C 1}=\sqrt{0.0847}=0.2911, \\
X_{C 2}=\sqrt[3]{0.1538}=0.5358, \\
X_{C}=\min \left(X_{C 1}, X_{C 2}\right)=0.2911
\end{gathered}
$$

By a similar calculation, we can obtain the corresponding initial catastrophe subordinate function value of upper indexes of SH and XFD from 2010 to 2014. The calculation results are shown in Table II.

Obviously, the upper indexes $A, B, C, D$ constitute a non-complementary butterfly catastrophe model, and their order of importance is $A>D>B>C$. According to the Formula (11), we can calculate the catastrophe progression value of upper indexes based on their initial catastrophe subordinate function value. Finally, we will get the two 
IMDS 117,9

enterprises' total catastrophe subordinate function value of different years through screening out the minimum catastrophe progression value of upper indexes (Tables III and IV).

\subsection{Discussion of findings}

From the above results above we can get the relevant change trend of the total catastrophe

1812 subordinate function value nearly five years in SH and XFD like Figure 4. Through horizontal and vertical comparison of the data, we can obtain the following information: In the past five years, the agricultural products cold chain logistics risk of SH and XFD have had a downward trend overall (figure as follows: the higher the value, the lower the risk). But in contrast, the cold chain logistics risk of XFD is higher than SH every year and SH has a larger advantage in agricultural products cold chain logistics. Actually, SH ranked far

\begin{tabular}{|c|c|c|c|c|c|c|c|c|c|c|c|}
\hline & Upper indexes & 2010 & 2011 & $\begin{array}{c}\text { SH } \\
2012 \\
\end{array}$ & 2013 & 2014 & 2010 & 2011 & $\begin{array}{l}\text { XFD } \\
2012 \\
\end{array}$ & 2013 & 2014 \\
\hline & $A$ & 0.0000 & 0.6843 & 0.8298 & 0.8577 & 0.8939 & 0.0000 & 0.0000 & 0.3904 & 0.5503 & 0.9186 \\
\hline i.l catastrophe & $D$ & 0.5028 & 0.8033 & 0.8841 & 0.9705 & 0.9859 & 0.0000 & 0.5355 & 0.7341 & 0.7812 & 0.8694 \\
\hline subordinate function & $B$ & 0.9225 & 0.8941 & 0.9492 & 0.9454 & 1.0000 & 0.2123 & 0.3996 & 0.6162 & 0.6771 & 0.6798 \\
\hline value of upper indexes & $C$ & 0.2911 & 0.4510 & 0.5523 & 0.7771 & 0.9253 & 0.0000 & 0.4318 & 0.6518 & 0.7321 & 0.9567 \\
\hline
\end{tabular}

Table III.

The catastrophe progression value of upper indexes

\begin{tabular}{lcccccccccc}
\hline & & \multicolumn{3}{c}{ SH } & & & & \multicolumn{1}{c}{ XFD } \\
Upper indexes & 2010 & 2011 & 2012 & 2013 & 2014 & 2010 & 2011 & 2012 & 2013 & 2014 \\
\hline$A$ & 0.0000 & 0.8272 & 0.9109 & 0.9261 & 0.9455 & 0.0000 & 0.0000 & 0.6249 & 0.7418 & 0.9584 \\
$D$ & 0.7952 & 0.9296 & 0.9598 & 0.9901 & 0.9953 & 0.0000 & 0.8120 & 0.9021 & 0.9210 & 0.9544 \\
$B$ & 0.9800 & 0.9724 & 0.9870 & 0.9861 & 1.0000 & 0.6788 & 0.7951 & 0.8860 & 0.9071 & 0.9080 \\
$C$ & 0.7813 & 0.8528 & 0.8881 & 0.9508 & 0.9846 & 0.0000 & 0.8454 & 0.9180 & 0.9395 & 0.9912 \\
\hline
\end{tabular}

Table IV.

The total catastrophe subordinate function value

\begin{tabular}{lcccccccccc}
\hline & \multicolumn{3}{c}{ SH } & \multicolumn{1}{c}{ XFD } \\
Aims & 2010 & 2011 & 2012 & 2013 & 2014 & 2010 & 2011 & 2012 & 2013 & 2014 \\
\hline Overall assessment & 0.0000 & 0.8272 & 0.8881 & 0.9261 & 0.9455 & 0.0000 & 0.0000 & 0.6249 & 0.7418 & 0.9080 \\
\hline
\end{tabular}

Figure 4.

The change curve of the total catastrophe subordinate function value

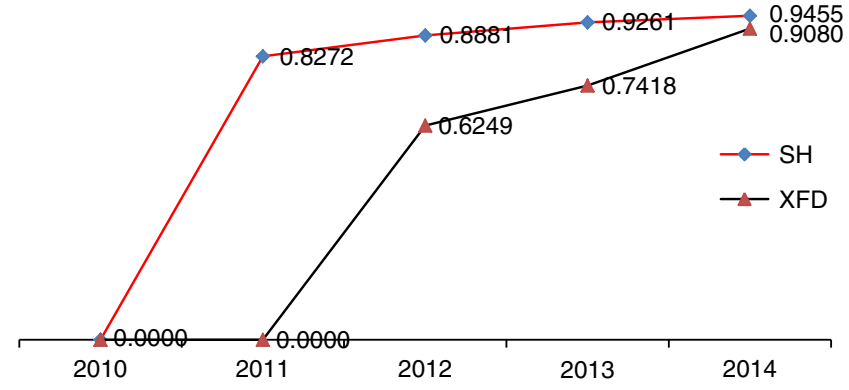


higher than XFD according to the list of top 50 cold chain logistics enterprises issued by the China National Cold Chain Committee those years (SH ranked 4th, XFD ranked 48th), which also reflects the reliability of the model from the side. We can obtain something from the Figure 5 that the catastrophe progression value of upper indexes of SH and XFD is overall in a safe range of $0.8 \sim 1.0$. However, compared to $\mathrm{SH}$, there are still large gaps in technical equipment $(A)$, product supply $(B)$, personnel organization $(D)$.

In recent years, $\mathrm{SH}$ always has a better rank than XFD in the top enterprises list of China's Cold Chain Logistics released by China's Cold-chain Logistics Professional Committee. In fact, SH's cold chain logistics belongs to the transport type, which has higher request for cold chain operation. On the contrary, the XFD belongs to the inventory type of cold chain logistics, and the overall level of its cold chain logistics is relatively low.

In general, the above conclusions are consistent with the reality, so the improved catastrophe progression assessment model designed in this paper can be well applied in the research on the risk assessment of agricultural cold chain logistics. Observing the calculation process, we can also find that the method could reduce the subjectivity in the process of decision-making largely because it considers the variable weights and attribute weights between different indexes at the same time. On the other hand, the calculation process of this method is also relatively simple and convenient.

Due to the improved catastrophe progression method proposed in this paper introduces a new maximum deviation method which gets the weight of each index by calculating the ratio of the total deviation of a specific index and the total deviation of all indexes in the system, so if the data from more enterprises are used, the final conclusions also will be more scientific and reasonable. Therefore, the methodology in this paper can ensure its generality.

\section{Conclusions}

This paper contributes to provide a new risk assessment model for agricultural products cold chain logistics by introducing an improved catastrophe progression method which is a combination of catastrophe progression method and a new maximum deviation method. In addition, the risk assessment index system of agricultural products cold chain logistics designed in this paper also can reflect the key risk factors of agricultural products cold chain logistics system objectively and reasonably. This paper not only has great academic contribution, but also a good practical significance. On the one hand, this paper research on agricultural products cold chain logistics from the perspective of risk assessment, and a new quantitative calculation model is put forward. The content and method discussed in this paper can enrich existing academic research system of cold chain logistics and agricultural products cold chain logistics. On the other hand, by adopting this new risk assessment framework model, firms engaged in fresh agricultural products cold chain logistics can get on a periodic risk assessment to reduce their risk of cold chain logistics. This assessment

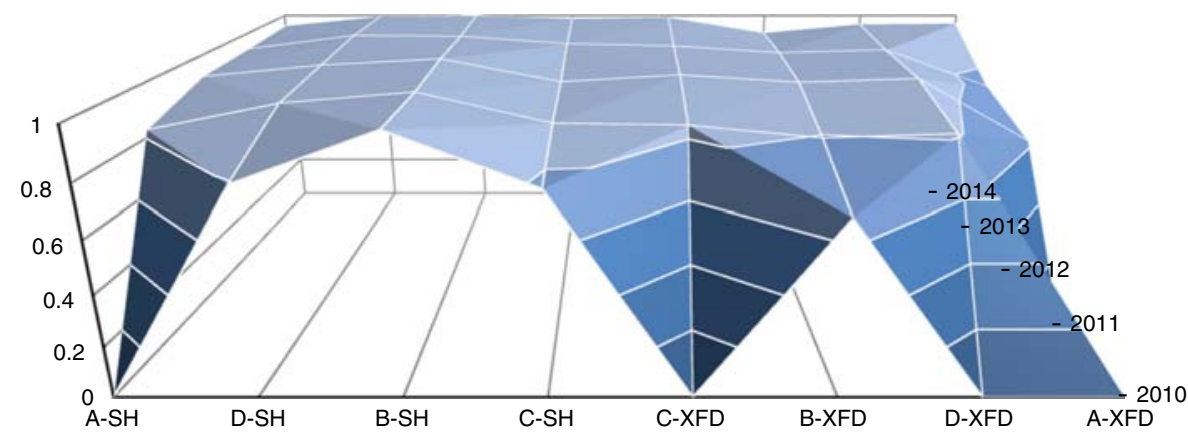

A new risk assessment model

1813
Figure 5.

The surface chart of assessment results 
IMDS 117,9

1814

framework model also has several implications for practitioners, especially for cold chain logistics managers, relevant management departments, and cold chain logistics management consultants.

The improved catastrophe progression assessment model overcomes the limitation of subjective empowerment, and it increases the objectivity and scientificity in the process of cold chain logistics risk assessment. It will allow practitioners to have a better assessment and understanding of all the possible risks related to agricultural products cold chain logistics, or support decision makers to make the decision relate to agricultural products cold chain logistics activities. Actually, we select two enterprises from agricultural cold chain logistics (Shuanghui Group and Beijing Xinfadi) as examples of research, and the results show that the model proposed in this paper is effective and reliable.

Although this paper has achieved certain implications in the study of agricultural products cold chain logistics risk assessment, it still has been subject to some limitations. First, the number of secondary indicators which were decomposed by the same primary indexes must not more than 4 since catastrophe theory requests that the maximum number of control variables could not exceed 4 when there is only one state variable. As a result, the risk assessment index system designed in this paper could not reflect all the factors that affect agricultural cold chain logistics risk comprehensively. It is possible to miss some important indicators. Second, it is necessary to understand that different firms may face different practical problems, and they should have their own risk assessment system. Although this paper attempts to use the decomposition method to identify the risk factors of the most representative of the agricultural cold chain logistics circulation mode around the world (the vegetable cold chain logistics mode in the USA) and interviews to experts, it is difficult for the risk assessment index system to ensure its generality.

A number of topics may be identified that would merit further research. First of all, in order to increase the comprehensiveness of the index system, the different types of catastrophe system can be further researched in the future to develop a higher dimensional structural model of catastrophe progression (the number of control variables can be extended to 5 or 6). Second, the future research can focus on constructing a general risk assessment index system of agricultural products cold chain logistics to meet the demand of risk assessment from different companies. Third, this study is focused on a risk assessment model for agricultural products cold chain logistics and it does not provide any advice on how to prevent the risk and control the risk, so it is also a research direction in the future.

\section{References}

Abad, E., Palacio, F. and Nuin, M. (2009), "RFID smart tag for traceability and cold chain monitoring of foods: demonstration in an intercontinental fresh fish logistic chain", Journal of Food Engineering, Vol. 93 No. 4, pp. 394-399.

Acosta, H. and Forrest, B.M. (2009), "The spread of marine non-indigenous species via recreational boating: a conceptual model for risk assessment based on fault tree analysis", Ecological Modelling, Vol. 220 No. 13, pp. 1586-1598.

Carullo, A., Corbellini, S. and Parvis, M. (2009), “A wireless sensor network for cold-chain monitoring”, IEEE Transactions on Instrumentation \& Measurement, Vol. 58 No. 5, pp. 1405-1411.

Cecilia, M.D.N.N., Nicometo, M. and Jean, P.E. (2014), "Improvement in fresh fruit and vegetable logistics quality: berry logistics field studies", Philosophical Transactions of the Royal Society a Mathematical Physical \& Engineering Sciences, Vol. 372 No. 2017, pp. 1-19.

Cieslak, T.C. (2011), "A fuzzy model for failure risk in water-pipe networks analysis", Ochrona Srodowiska, Vol. 33, pp. 35-40.

Caputo, A.C., Palumbo, M. and Tartaglia, R. (2004), "Fault tree analysis for risk assessment in the Borexino experiment”, Process Safety Progress, Vol. 23 No. 2, pp. 121-131. 
Chen, X.H. and Yang, L. (2013), "Obstacle diagnosis model based on the catastrophe progression method and its applications for the small and medium-sized enterprises", Systems EngineeringTheory \& Practice, Vol. 33 No. 6, pp. 1479-1485.

Defraeye, T., Nicolai, B. and Kirkman, W. (2016), "Integral performance evaluation of the fresh-produce cold chain: a case study for ambient loading of citrus in refrigerated containers", Postharvest Biology \& Technology, Vol. 112, pp. 1-13.

Fabre, F., Pierre, J.S. and Dedryver, C.A. (2006), "Barley yellow dwarf disease risk assessment based on Bayesian Modelling of aphid population dynamics”, Ecological Modelling, Vol. 193 No. 4, pp. 457-466.

Grassi, A., Gamberini, R. and Mora, C. (2009), "A fuzzy multi-attribute model for risk evaluation in workplaces”, Safety Science, Vol. 47 No. 5, pp. 707-716.

Gierczak, M. (2014), "The quantitative risk assessment of MINI, MIDI and MAXI horizontal directional drilling projects applying Fuzzy fault tree analysis", Tunnelling and Underground Space Technology, Vol. 43 No. 7, pp. 67-77.

Golubitsky, M. (1978), "An Introduction to catastrophe theory and its applications”, Siam Review, Vol. 20 No. 2, pp. 65-100.

Jin, T., Yahui, W. and Xuemei, F. (2013), "Monitoring system of cold chain logistics for farm fresh problem", Journal of Jilin University (Engineering and Technology Edition), Vol. 43 No. 6, pp. 1707-1711.

James, S.J., James, C. and Evans, J.A. (2006), "Modelling of food transportation systems - a review", International Journal of Refrigeration, Vol. 29 No. 6, pp. 947-957.

Joshi, R., Banwet, D.K. and Shankar, R. (2011), “A Delphi-AHP-TOPSIS based benchmarking framework for performance improvement of a cold chain”, Expert Systems with Applications, Vol. 38 No. 8, pp. 10170-10182.

Kuo, J.C. and Chen, M.C. (2010), "Developing an advanced multi-temperature joint distribution system for the food cold chain", Food Control, Vol. 21 No. 4, pp. 559-566.

Lutjen, M., Dittmer, P. and Veigt, M. (2013), "Quality driven distribution of intelligent containers in cold chain logistics networks", Production Engineering, Vol. 7 No. 2, pp. 291-297.

Lixin, L., Weizhou, Z. and Zhiye, L. (2013), "Development and application of time - temperature indicators used on food during the cold chain logistics", Packaging Technology and Science, Vol. 26 No. S1, pp. 80-90.

Liyuan, C., Zhenxing, W. and Yunyan, W. (2010), "Ingestion risks of metals in groundwater based on TIN model and dose-response assessment - a case study in the Xiangjiang watershed, central-south China”, Science of the Total Environment, Vol. 408 No. 16, pp. 3118-3124.

Manning, L., Baines, R.N. and Chadd, S.A. (2006), "Quality assurance models in the food supply chain", British Food Journal, Vol. 108 No. 2, pp. 91-104.

O'Shea, D. (2001), "An exposition of catastrophe theory and its applications to phase transitions", American Journal of Respiratory Cell and Molecular Biology, Vol. 24 No. 4, pp. 469-474.

Rediers, H., Claes, M. and Peeters, L. (2008), "Evaluation of the cold chain of fresh-cut endive from farmer to plate", Postharvest Biology and Technology, Vol. 51 No. 2, pp. 257-262.

Shabani, A., Saen, R.F. and Torabipour, S.M.R. (2012), "A new bench marking approach in cold chain", Applied Mathematical Modelling, Vol. 36 No. 1, pp. 212-224.

Wang, Y.M. (1998), "Using the method of maximizing deviations to make decision for multiindicis", Systems Engineering and Electronics, Vol. 7, pp. 24-26.

Wang, Y.M. and Elhag, T.M.S. (2006), "Fuzzy TOPSIS method based on alpha level sets with an application to bridge risk assessment”, Expert Systems with Applications, Vol. 31 No. 2, pp. 309-319.

Xinqing, X., Qile, H. and Zetian, F. (2016), "Applying CS and WSN methods for improving efficiency of frozen and chilled aquatic products monitoring system in cold chain logistics", Food Control, Vol. 60, pp. 656-666.

Xuefeng, L., Ying, W. and Xi, C. (2012), "Cold chain logistics system based on cloud computing", Concurrency \& Computation Practice \& Experience, Vol. 24 No. 17, pp. 2138-2150. 
IMDS

117,9

1816
Xinqing, X., Xiang, W. and Xiaoshuan, Z. (2015), "Effect of the quality property of table grapes in cold chain logistics-integrated WSN and AOW”, Applied Sciences, Vol. 5 No. 4, pp. 747-760.

Yujun, W., Jianjun, Y. and Xiaomin, Z. (2015), "Developing an ontology-based cold chain logistics monitoring and decision system", Journal of Sensors, Vol. 2 No. 4, pp. 1-8.

Zeeman, E.C. (1979), “Catastrophe theory: selected papers 1972-77”, Journal of Applied Mechanics, Vol. 46 No. 32, pp. 813-816.

Zhang, T.J., Ren, S.X. and Shu-Gang, L.I. (2009), "Application of the catastrophe progression method in predicting coal and gas outburst", Mining Science \& Technology, Vol. 19 No. 4, pp. 430-434.

\section{About the authors}

Hao Zhang is currently working as an Associate Professor in the Business School at Beijing Technology and Business University. He was awarded a $\mathrm{PhD}$ in Engineering. His current research areas include logistics system optimization and simulation, complex system modeling and simulation, regional development strategy. He focuses on the study of the data models and decisions, and his research has been widely published.

Bin Qiu is a Master Graduate Student majored in Logistics Engineering in the School of Economics and Management from Beijing Jiaotong University. His current research includes logistics systems engineering. Bin Qiu is the corresponding author and can be contacted at: qiubin18@163.com

Keming Zhang is an Associate Professor in the School of Economics and Management at the Beijing Jiaotong University. Her current research includes Logistics Systems Engineering and Logistics Organization Circulation.

For instructions on how to order reprints of this article, please visit our website: 